\title{
Modeling the Effects of Late Cycle Oxygen Enrichment on Diesel Engine Combustion and Emissions
}

\author{
D. K. Mather and D. E. Foster \\ University of Wisconsin - Madison
}

\author{
R. B. Poola and D. E. Longman \\ Argonne National Laboratory
}

\author{
A. Chanda, and T. J. Vachon \\ Caterpillar, Inc.
}

\section{Abstract}

A multidimensional simulation of Auxiliary Gas Injection (AGI) for late cycle oxygen enrichment was exercised to assess the merits of AGI for reducing the emissions of soot from heavy duty diesel engines while not adversely affecting the $\mathrm{NO}_{x}$ emissions of the engine. Here, AGI is the controlled enhancement of mixing within the diesel engine combustion chamber by high speed jets of air or another gas. The engine simulated was a Caterpillar 3401 engine. For a particular operating condition of this engine, the simulated soot emissions of the engine were reduced by $80 \%$ while not significantly affecting the engine-out $\mathrm{NO}_{x}$ emissions compared to the engine operating without AGI. The effects of AGI duration, timing, and orientation are studied to confirm the window of opportunity for realizing lower engine-out soot while not increasing engine out $\mathrm{NO}_{x}$ through controlled enhancement of in-cylinder mixing. These studies have shown that this window occurs during the late combustion cycle, from 20 to $60 \mathrm{crank}$ angle degrees after top-dead-center. During this time, the combustion chamber temperatures are sufficiently high that soot oxidation increases in response in increased mixing, but the temperature is low enough that $\mathrm{NO}_{x}$ reactions are quenched. The effect of the oxygen composition of the injected air is studied for the range of compositions between $21 \%$ and $30 \%$ oxygen by volume. This is the range of oxygen enrichment that is practical to produce from an air separation membrane. Simulations showed that this level of oxygen enrichment is insufficient to provide an additional benefit by either increasing the level of soot oxidation or prolonging the window of opportunity for increasing soot oxidation through enhanced mixing.

\section{Introduction}

The diesel engine industry faces a major challenge as they strive to meet increasingly stringent standards for emissions of smoke and oxides of nitrogen $\left(\mathrm{NO}_{x}\right)$. AGI for late cycle oxygen enrichment is a promising technology whereby jets of air or another gas are employed to control and favorably enhance the mixing within the diesel-engine combustion chamber. Typically, the goal of AGI is to enhance the mixing of soot and air during the later portion of the combustion when soot oxidation can be increased, but $\mathrm{NO}_{x}$ formation has ceased. Thus, AGI is a method of achieving a reduction of engine-out soot without an accompanying increase in $\mathrm{NO}_{x}$, unlike conventional soot reduction strategies.

The experiments by Yamaura et al. [1] were conducted to investigate the effects of the injected gas composition on the reduction of soot emissions from a diesel engine with AGI. The gas composition was found to be an important factor influencing the soot reduction benefit from AGI. The approach to AGI investigated here considers a novel concept for altering the composition of the injected air. The oxygen content of the injected air is increased in an attempt to enhance its effectiveness at oxidizing soot. This oxygen enriched air could be supplied by an air-separation membrane capable of providing oxygen enrichment up to $35 \%$ by volume [2]. Factors which influence the impact to soot reduction from such a system were investigated computationally using a modified version of the KIVA-3v multidimensional engine simulation code, with submodels for diesel sprays, combustion, and high-speed gas jets [3]. The baseline engine for these simulations was the Caterpillar 3401 heavy-duty truck engine which has been successfully simulated in many studies $[4,5,6]$. Initial studies of AGI by the authors focused on both the present engine and a TACOM engine for which experimental AGI data was available for comparison to the simulations [3].

\section{Combustion Modeling of Auxiliary Gas Injection}

The simulations of AGI for late cycle oxygen enrichment were conducted using the Caterpillar 3401 as the baseline engine. The specifications of this engine are provided in Table 1. This engine uses a central 6-hole fuel injector. The simulations took advantage of the 6-fold symmetry of this combustion system by modeling only a 60 degree sector of the combustion chamber as shown in Fig. 1. The gas injector for AGI was located near the axis of the combustion chamber as indicated in Fig. 1(a). This arrangement provided one gas injector nozzle hole for each sector of the combustion chamber, thus preserving the symmetry of the combustion system. The pitch angle, $\phi$, shown in Fig. 1(b) 


\begin{tabular}{|l|l|}
\hline engine & Caterpillar 3401 \\
\hline bore & $13.719 \mathrm{~cm}$ \\
\hline stroke & $16.51 \mathrm{~cm}$ \\
\hline connecting rod length & $26.162 \mathrm{~cm}$ \\
\hline displacement & $2.44 \mathrm{l}$ \\
\hline compression ratio & $15: 1$ \\
\hline intake valve timing & closed $-147 \mathrm{CA}$ \\
\hline exhaust valve timing & open $136 \mathrm{CA}$ \\
\hline intake pressure & $184 \mathrm{kPa}$ \\
\hline intake temperature & $310 \mathrm{~K}$ \\
\hline engine speed & $1600 \mathrm{rpm}$ \\
\hline equivalence ratio $\phi$ & 0.4 \\
\hline
\end{tabular}

Table 1: Caterpillar single cylinder oil test engine specifications.

\begin{tabular}{|l|l|}
\hline number of orifices & 6 \\
\hline orifice diameter & $0.07 \mathrm{~cm}$ \\
\hline orifice location & $0.5 \mathrm{~cm}$ from cylinder axis \\
\hline orifice orientation & $0-60$ degrees pitch \\
\hline gas composition & $21 \%-30 \%$ oxygen \\
\hline delivery pressure & $500,2000,3000 \mathrm{psi}$ \\
\hline reservoir temperature & $\begin{array}{l}\text { adiabatic compression tem- } \\
\text { perature }\end{array}$ \\
\hline $\begin{array}{l}\text { beginning of gas in- } \\
\text { jection (BOGI) }\end{array}$ & $20-80 \mathrm{CA} \mathrm{ATDC}$ \\
\hline $\begin{array}{l}\text { duration of gas injec- } \\
\text { tion (DOGI) }\end{array}$ & $40-80 \mathrm{CA}$ \\
\hline injected mass & $\sim 0.2 \mathrm{~g}$ \\
\hline $\begin{array}{l}\text { estimated compres- } \\
\text { sion power }\end{array}$ & $\sim 1.72 \mathrm{~kW} /$ cylinder \\
\hline
\end{tabular}

Table 2: Simulated auxiliary gas injection specifications.

refers to the angle the gas jet makes with respect to the axis of the combustion chamber. The specifications for the simulated gas injector are provided in Table 2 .

In the previous study of AGI in the Caterpillar engine [3] the location of the AGI was from the periphery of the combustion chamber. The objectives of the present study are twofold: to investigate whether similar emission reductions found in the previous study are achievable when the AGI is from the axis of the combustion chamber, as would be the case if the AGI were incorporated into the fuel injector, and to investigate the effects of injecting oxygen enriched air upon the engine out emissions.

Figure 2 shows a comparison of the soot and $\mathrm{NO}_{x}$ emissions for fuel injection timings from -9 to +3 CA ATDC predicted by the KIVA code employed for this study and the measured emissions for the engine.

The action of AGI on this diesel combustion system is shown as rendered computational results in Figs. 3(a), $3(\mathrm{~b})$, and 3(c) The 60 degree sector of the combustion chamber is shown in Fig. 3(a) at top-dead-center. The fuel injection started at -9 CA ATDC, and the injected

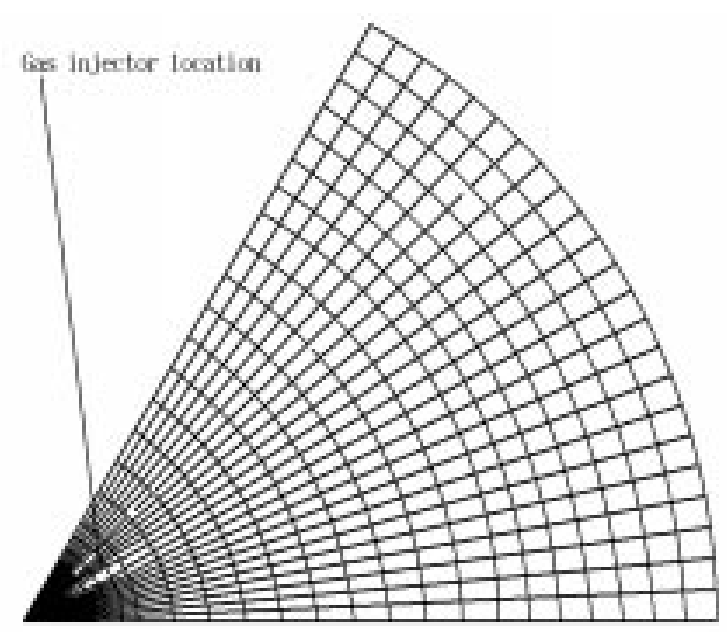

(a) Top view

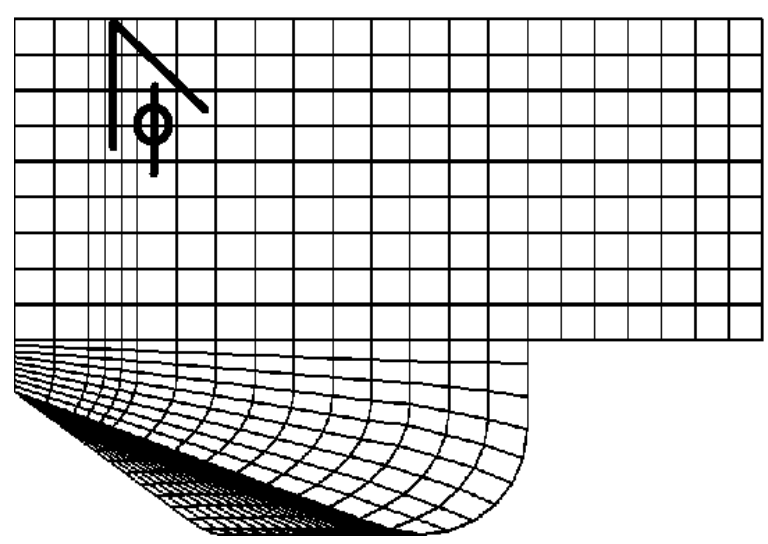

(b) Side view of showing piston bowl.

Figure 1: Computational grid employed for modeling AGI. $\phi$ indicates the AGI pitch angle.

liquid diesel fuel is represented as small red spheres. The location of the soot and the $\mathrm{NO}_{x}$ are indicated by the grey and the red clouds, respectively. Figure $3(\mathrm{~b})$ shows the location of the soot and $\mathrm{NO}_{x}$ clouds at $20 \mathrm{CA}$ ATDC, which is the instant that the AGI begins. Figure 3(c) shows the interaction of the AGI with the soot cloud. Here the AGI, represented by the blue cloud, has engulfed the soot cloud. In this way, the AGI is able to exert a strong influence on the soot oxidation by enhancing mixing during the later portion of the combustion cycle.

The computational investigation of the merits of AGI for late cycle oxygen enrichment is divided into four studies to characterize the effect of the orientation, duration, timing, composition, and delivery pressure on the ability of AGI to reduce engine out soot without increasing $\mathrm{NO}_{x}$. 


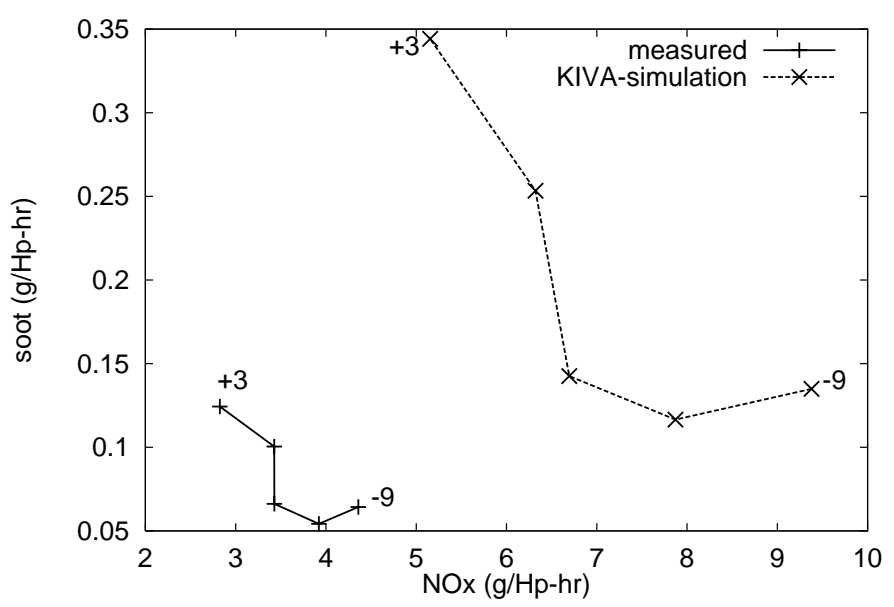

Figure 2: Measured and simulated soot- $\mathrm{NO}_{x}$ tradeoff for the baseline engine.

\section{Effects of AGI Orientation, Duration, and Delivery Pressure}

In this study the effect of the AGI orientation and duration on the emissions was characterized for two different AGI injection pressures. The orientation of the AGI in all cases was radially out from the cylinder axis. The pitch angle, the angle the jet made with respect to the cylinder axis, was varied from 0 to 60 degrees. The duration of gas injection (DOGI) was measured in engine crank angles and varied from 40 to $80 \mathrm{CA}$. Finally, two AGI delivery pressures of $2000 \mathrm{psi}$ and $3000 \mathrm{psi}$ were simulated in this phase of the study. A lower delivery pressure (500 psi) AGI was investigated in a subsequent study. For all the present simulations, the beginning of gas injection (BOGI) remained at $20 \mathrm{CA}$ ATDC, the oxygen purity of the injected gas was $25 \%$ by volume, and the start of fuel injection was $-9 \mathrm{CA}$ ATDC.

The results of these simulations are shown in Figs. 4(a) and 4(b) for 2000 psi AGI. Figure 4(a) shows the simulated engine-out soot levels for the range of AGI durations and orientations considered. The dotted line shows the simulated engine out soot level for the baseline engine operating without AGI. For this operating condition, AGI was very effective at reducing engine out soot. Increasing the AGI DOGI beyond $40 \mathrm{CA}$ had no significant additional benefit for soot reduction. Finally, for this operating condition, the optimum AGI orientation for reducing engine-out soot was found to be 45 degrees pitch angle.

Figure 4(b) shows the corresponding engine out $\mathrm{NO}_{x}$ for these simulations. Here again, the dashed line shows the engine out $\mathrm{NO}_{x}$ level for the baseline engine. For this set of simulations, the engine-out $\mathrm{NO}_{x}$ varies between 9 and 10 $\mathrm{g} / \mathrm{hp}-\mathrm{hr}$, which is not a significant variation. These simulations demonstrated the window of opportunity during the combustion cycle for significantly enhancing the oxidation of soot while not adversely affecting the engine out $\mathrm{NO}_{x}$.

This window of opportunity for significantly reducing

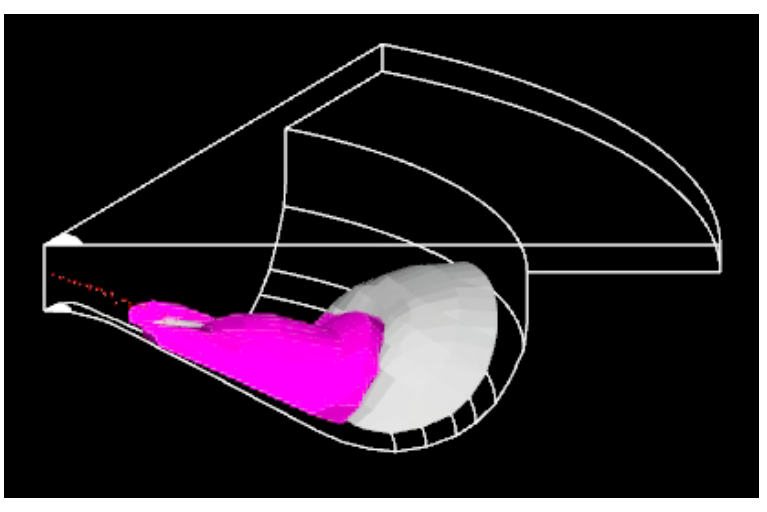

(a) $\mathrm{TDC}$

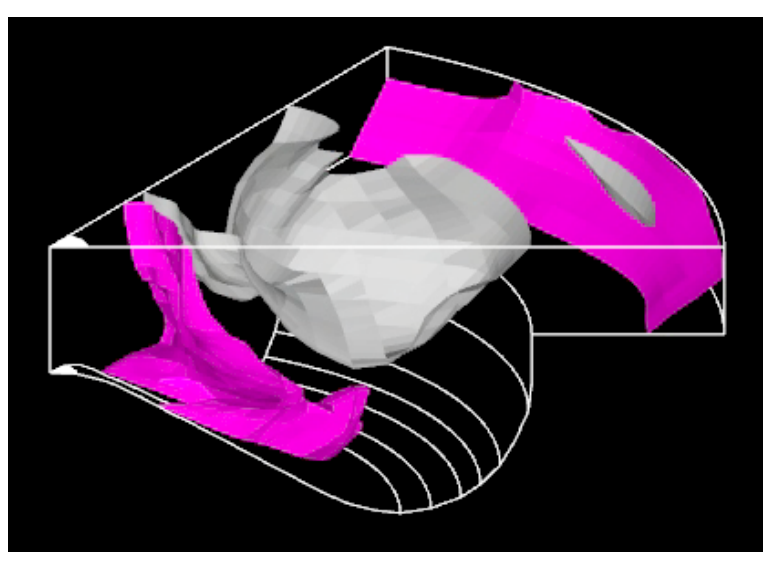

(b) 20 CA ATDC

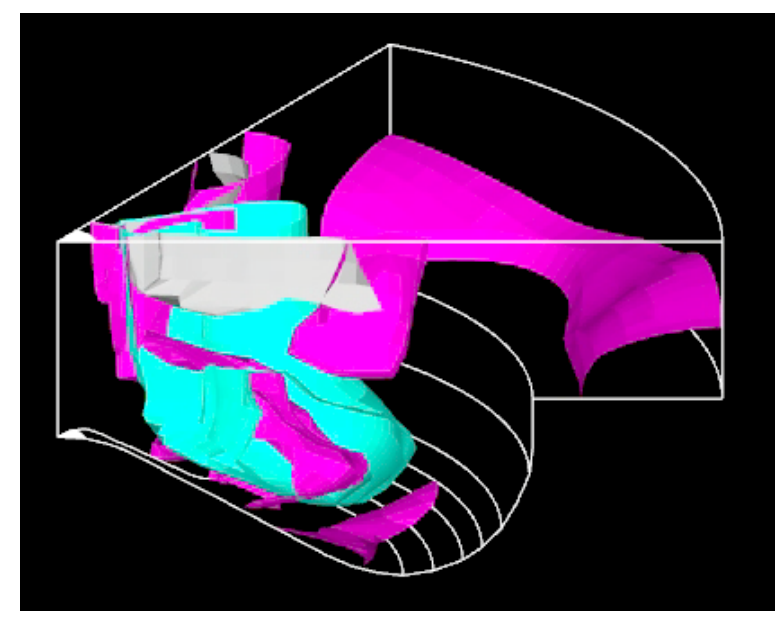

(c) $30 \mathrm{CA}$ ATDC

Figure 3: Engine during the expansion stroke showing the locations of the soot cloud (grey), the $\mathrm{NO}_{x}$ cloud (red), and the AGI (blue). 


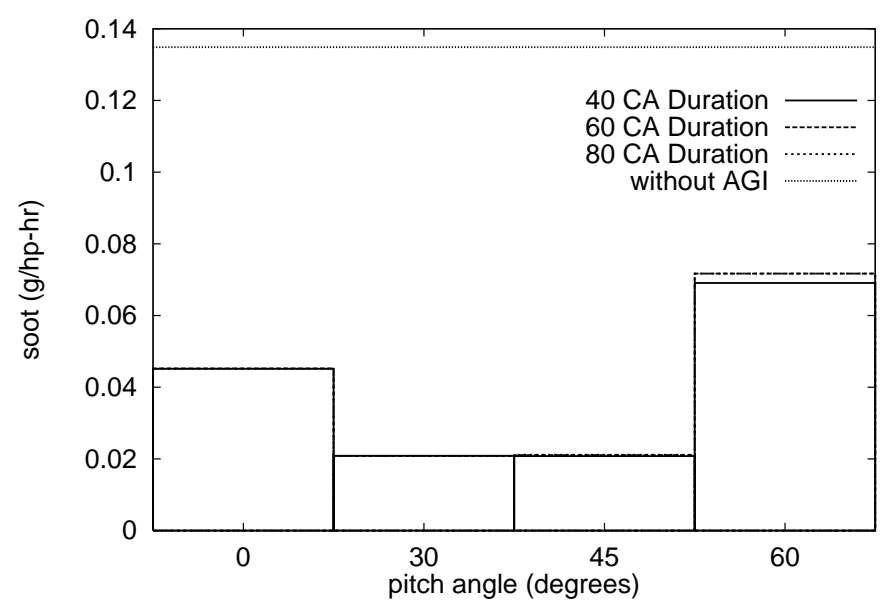

(a) engine-out soot

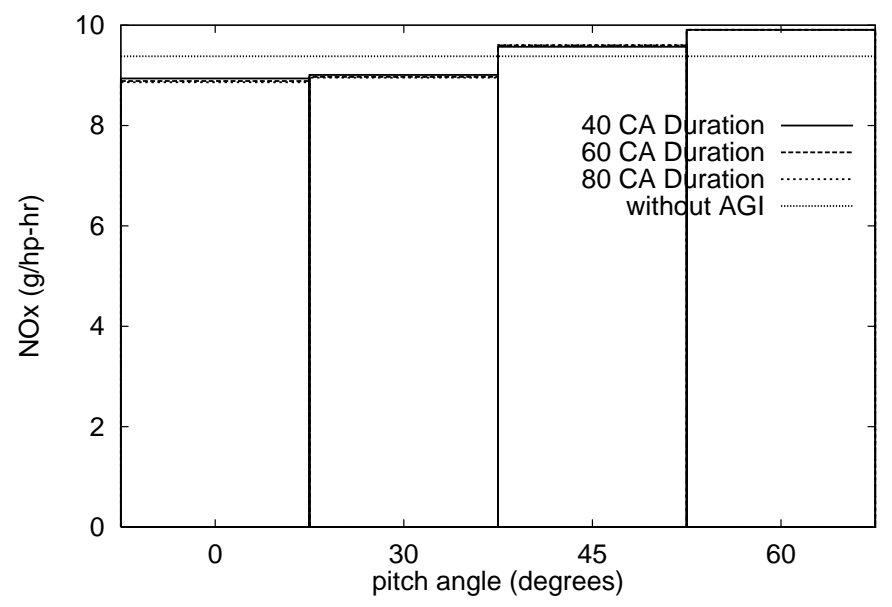

(b) engine-out $\mathrm{NO}_{x}$

Figure 4: Effect of AGI orientation and duration on engineout emissions.

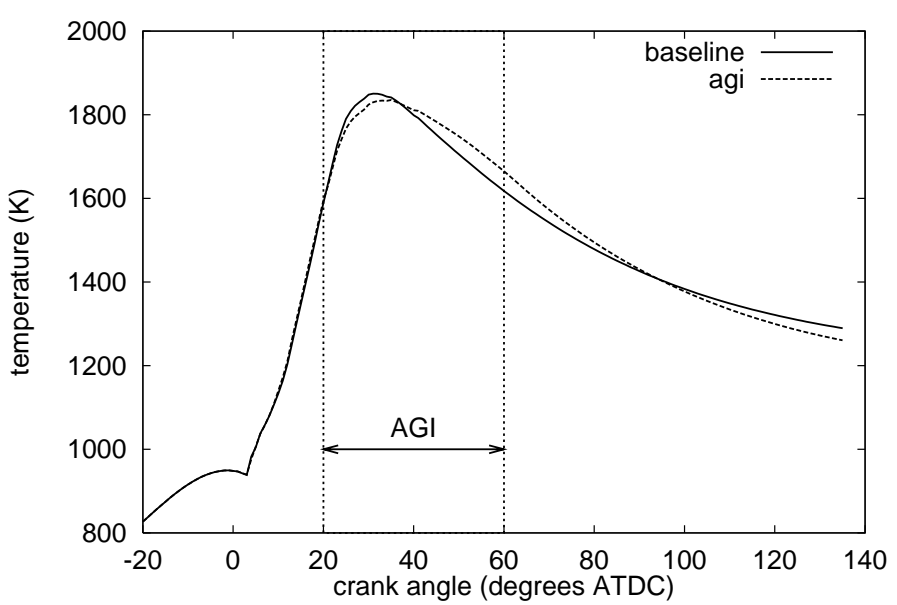

Figure 5: The influence of AGI on the evolution of the combustion chamber temperature.

engine-out soot while not increasing the engine-out $\mathrm{NO}_{x}$ can be seen by examining the evolution of temperature, soot, and $\mathrm{NO}_{x}$ during the combustion. Figure 5 shows the bulk gas temperature during the combustion for the engine operating with and without AGI as the baseline. For this case, AGI BOGI is $20 \mathrm{CA}$ ATDC and DOGI is $40 \mathrm{CA}$. The period of AGI is indicated on the figure. The AGI occurs while the bulk gas temperature is above the $1400 \mathrm{~K}$ soot oxidation quench temperature. The AGI slightly increases the bulk gas temperature from 40 to $80 \mathrm{CA}$ ATDC.

Figure 6 shows the in-cylinder soot evolution for the engine operating with and without AGI. As can be seen, the soot formation begins shortly after TDC. The peak soot is formed by $25 \mathrm{CA}$ ATDC, and the peak soot levels are very similar for the engine operating with or without AGI. The effect of AGI is felt after 40 CA ATDC. When the engine is operated with AGI, the soot oxidation continues at the initial high rate until $60 \mathrm{CA}$ ATDC, while the decrease in soot level within the engine operating without AGI begins at $40 \mathrm{CA}$ ATDC. From Fig. 5 we see that the bulk gas temperature remains well above the $1400 \mathrm{~K}$ soot oxidation quench temperature. The effect of AGI is to prevent the soot oxidation reactions from slowing due to a lack of oxygen.

Figure 7 shows the in-cylinder $\mathrm{NO}_{x}$ evolution for the engine operating with and without AGI. As with the soot, the $\mathrm{NO}_{x}$ formation begins just after TDC, but the $\mathrm{NO}_{x}$ has reached its maximum, engine-out level by $40 \mathrm{CA}$ ATDC, the time when AGI is influencing soot. The features of the $\mathrm{NO}_{x}$ evolution curves are identical for the engine operating with or without AGI. In this particular case, the engine had a slightly lower engine-out $\mathrm{NO}_{x}$ when AGI was used.

Finally, the effect of AGI on engine power is considered. In order to be a viable technology for reducing engine emissions, the emissions benefits from AGI must be weighed against the parasitic power required to produce the gas jets. For the engine simulated, AGI actually increases the 


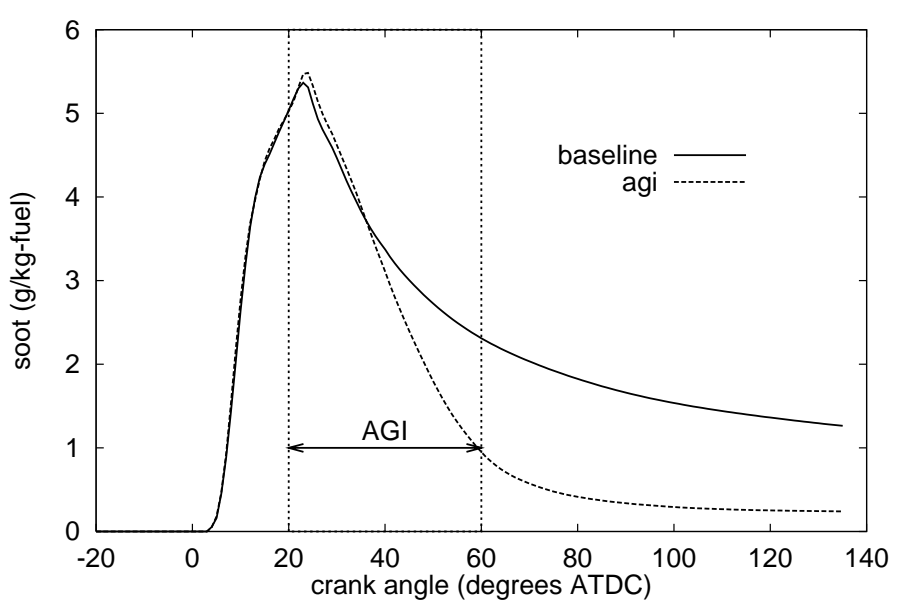

Figure 6: The influence of AGI on the evolution of the combustion chamber soot.

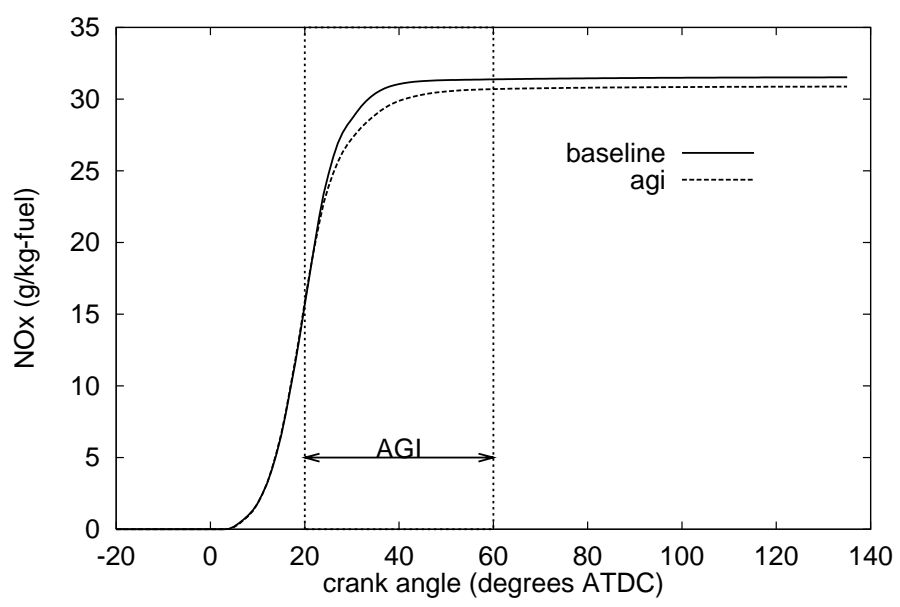

Figure 7: The influence of AGI on the evolution of the combustion chamber $\mathrm{NO}_{x}$.

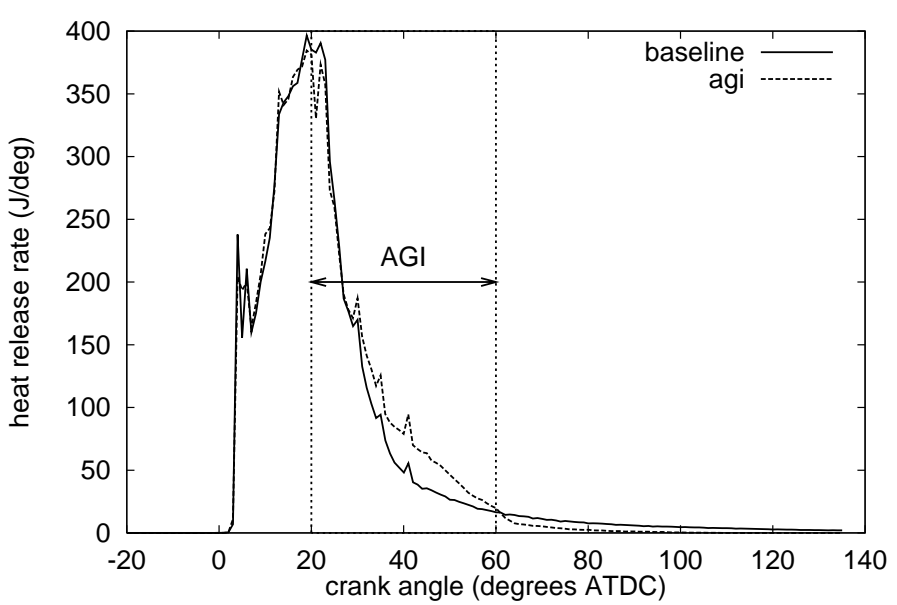

Figure 8: The influence of AGI on the evolution of the heat release rate.

power produced by the engine. For the particular operating condition shown in the temperature and emissions evolution curves, the indicated engine power was increased by $1.86 \mathrm{~kW}$. The estimated compression work to deliver air at $13.8 \mathrm{MPa}$ is about $1.72 \mathrm{~kW}$, as reported in Table 2 . Thus the reduction in emissions is accomplished without a large penalty in engine efficiency.

The extra power produced by the engine when it is operated with AGI is reflected in the heat release rates for the engine. Figure 8 shows that there is an increased heat release rate during the AGI period. The source of this extra power is extra mixing releasing more of the energy in the fuel earlier in the expansion stroke. Additionally, some of energy of the AGI jet itself is recovered by expanding the gas within the combustion chamber.

This study demonstrates the merit of AGI for reducing engine-out soot while not increasing engine-out $\mathrm{NO}_{x}$ by means of enhancing mixing during the later potion of the combustion cycle. The window of opportunity was between 20 and 60 CA ATDC. Furthermore, the simulations predict that the shorter AGI duration was as effective as the longer duration gas injection. The simulations also identified 45 degrees pitch angle as an optimum orientation of the AGI for this combustion system.

\section{Fuel Injection and AGI Timing}

The most common strategy for reducing $\mathrm{NO}_{x}$ from a diesel engine is to retard the fuel injection timing. In this study, the interaction of fuel injection timing and AGI timing were characterized. The start of fuel injection was varied from -9 CA ATDC to +4 CA ATDC. The AGI timing was varied from a BOGI at $20 \mathrm{CA}$ ATDC to an advanced BOGI at $10 \mathrm{CA}$ ATDC. The composition of the injected gas was $25 \%$ oxygen by volume. The orientation of the AGI was 45 degrees, the optimum orientation for soot reduction from the previous study. The pressure of the injected gas was $2000 \mathrm{psi}$, and the AGI DOGI was $40 \mathrm{CA}$. The result of these 


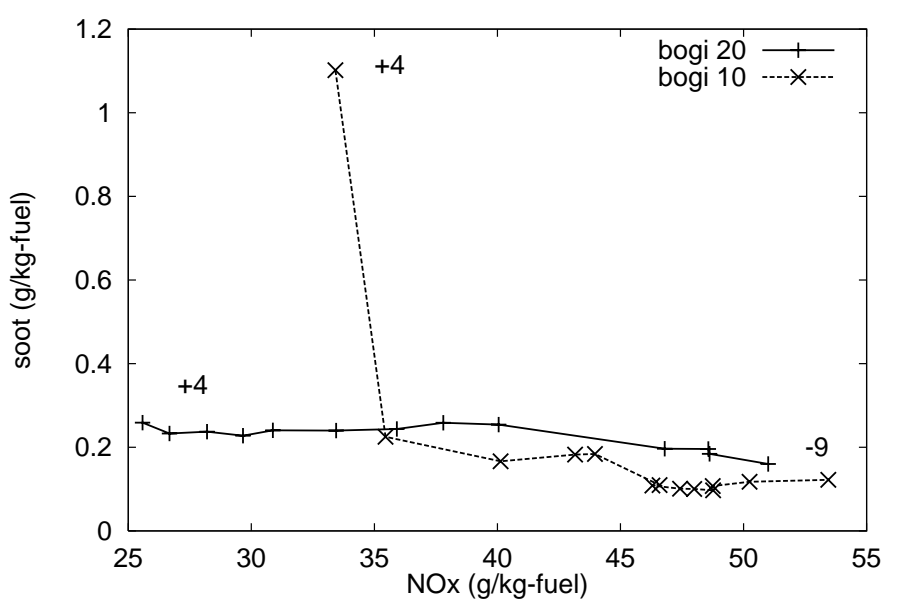

Figure 9: The influence of AGI and fuel injection timing on engine-out emissions.

studies are summarized as a soot- $\mathrm{NO}_{x}$ tradeoff in Fig. 9. The simulations predict that a dramatic flattening of the soot- $\mathrm{NO}_{x}$ tradeoff occurs when AGI is employed, which would permit the engine to operate at much retarded fuel injection timings without increasing the engine out soot. A comparison of the effects of the earlier and the later BOGI shows that the early BOGI has a higher engine out $\mathrm{NO}_{x}$ level and has a higher engine out soot level at the extreme retarded fuel injection timing. From the previous study, it was shown that increasing DOGI beyond $40 \mathrm{CA}$ had little additional benefit. The other option for increasing the time when AGI enhances mixing is to start the AGI earlier. This study shows that, for this combustion system, starting the AGI earlier than $20 \mathrm{CA}$ ATDC undesirably increases engine-out $\mathrm{NO}_{x}$.

\section{Effect of AGI Oxygen Purity}

As this project falls within the larger context of ANL's ongoing study of membrane based air composition control for diesel engines, the effect of AGI when the injected air oxygen composition is modified using air separation membranes was investigated. For this study the composition of the injected air was varied from $21 \%$ to $30 \%$ oxygen by volume, which represents the range from no oxygen enrichment up to the maximum enrichment level that can be efficiently produced with the present membrane technology. Figure 10 shows the soot- $\mathrm{NO}_{x}$ tradeoffs for AGI with $21 \%$, $25 \%$, and $30 \%$ oxygen by volume. The soot- $\mathrm{NO}_{x}$ tradeoff for the engine operating without AGI is included for comparison. As can be readily seen, each of the injected gases were equally effective at reducing the emissions from the engine. It is predicted that there was no significant additional benefit to the effectiveness of AGI at reducing engine out soot by increasing the oxygen composition of the injected gas.

The reason for the small effect on engine-out soot from altering the composition of the injected gas is that the AGI

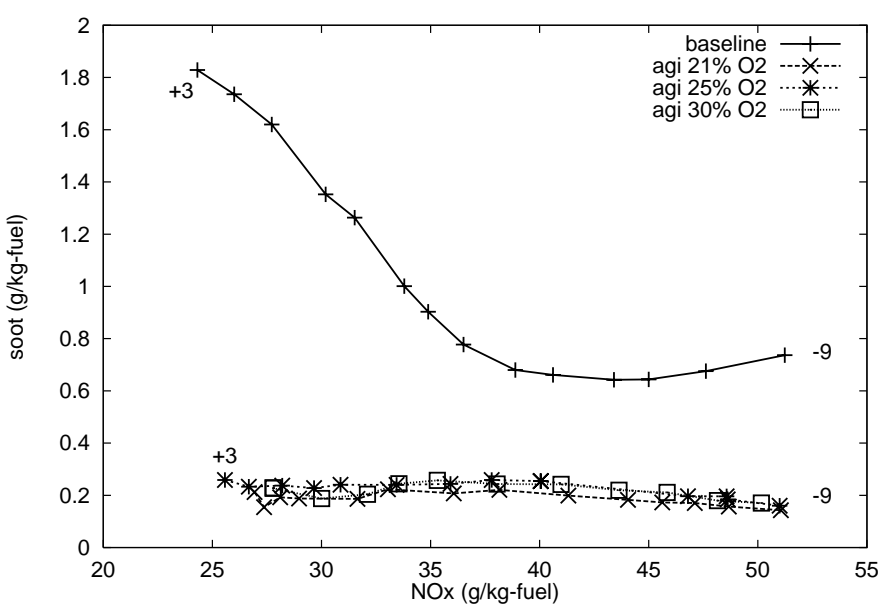

Figure 10: The influence of AGI gas composition on engineout emissions.

jet became diluted from entraining combustion chamber gas. The jet entrains so much of the ambient combustion chamber gas that the AGI jet effectively has the composition of the combustion chamber gas, regardless of the injected gas composition for the small range of oxygen enrichment levels investigated.

\section{Low AGI Pressure at Retarded Timings}

In this study, the effectiveness of AGI at late injection timings was investigated to see if there would be a more pronounced effect from the injected gas composition at the retarded BOGI. As the bulk combustion chamber temperature falls, the added oxygen in the injected gas would permit soot oxidation to continue at lower temperatures. It was hoped that the higher oxygen concentration would offset the slowing of the soot reaction rates from the lower combustion chamber temperature during the late expansion stroke. Another benefit of retarding the BOGI would be that the cylinder pressure has decreased at the later timings, reducing the required delivery pressure of the injected gas for the same mass flow rate. However, the simulations showed that late AGI is not very effective at enhancing soot oxidation as compared with the early AGI timings.

Figure 11 shows the engine out soot levels for these simulations. The earliest BOGI is $40 \mathrm{CA}$ ATDC. It was not feasible to begin AGI earlier because the injected gas was simulated as flowing from a 500 psi reservoir. At the earlier timings, the combustion chamber pressure was above the AGI reservoir pressure. Three AGI conditions were simulated: low pressure (500 psi) AGI at $25 \%$ and low pressure (500 psi) AGI at 30\% oxygen by volume, and high pressure (2000 psi) AGI at $25 \%$ by volume for comparison. The dashed line indicates the engine out soot level when the engine is operated without AGI. For this operating condition, there was just a slight change from the baseline soot level when the engine was operated with low pressure AGI. Slightly more soot reduction was obtained 


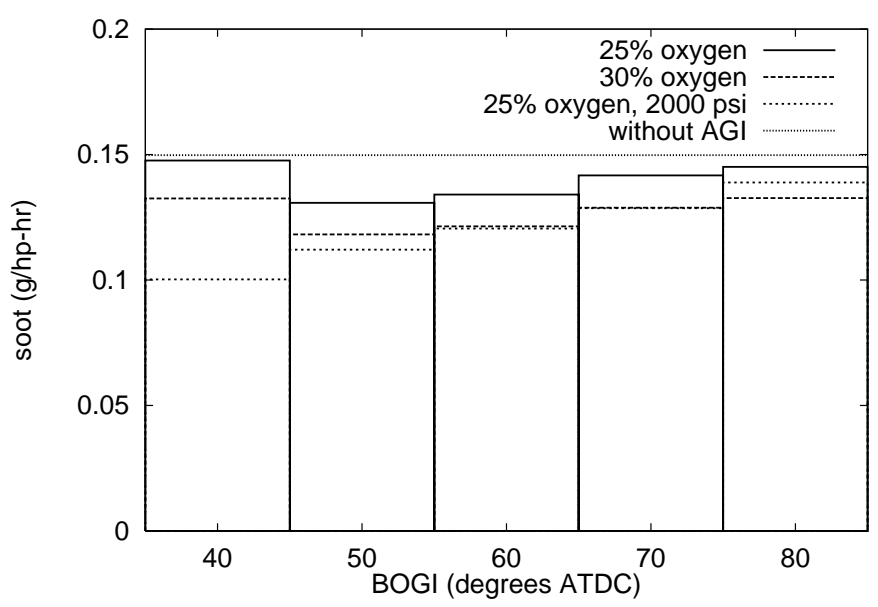

Figure 11: The influence of 500 psi delivery pressure AGI on engine-out soot.

when the injected gas had a higher oxygen content. But even with 2000 psi AGI, the soot reduction was much less than was observed with $20 \mathrm{CA}$ ATDC BOGI. Thus, these simulations imply that the window for increasing soot oxidation cannot be extended to the late combustion stage by increasing the oxygen content of the injected gas.

\section{Conclusions}

Multidimensional engine simulations of a heavy-duty diesel engine operating with AGI were conducted to study the merits of AGI for late cycle oxygen enrichment as a strategy for reducing engine-out soot without increasing engine out $\mathrm{NO}_{x}$. The simulations incorporated the state-of-theart submodels for diesel engine spray and combustion, and a submodel for the near nozzle dynamics of the high speed gas jet produced by the AGI. Over 80 simulations, each requiring more than 36 hours of HP-735 computer time, were performed to investigate the influence of AGI parameters on the effectiveness of AGI for reducing engine-out soot.

The following conclusions can be drawn from this investigation:

1. AGI is predicted to be effective at reducing soot independently of $\mathrm{NO}_{x}$. Soot reductions of up to $80 \%$ were predicted in simulations with AGI, with slight changes in the engine out $\mathrm{NO}_{x}$.

2. The performance of AGI is sensitive to the timing and orientation of the gas jet within the combustion chamber. Because AGI is locally influencing conditions within the combustion chamber, it is essential that the AGI jet encounters the soot at the proper time.

3. These simulations have identified the window of opportunity when enhanced mixing from AGI favorably influences mixing and increases soot oxidation without increasing the formation of $\mathrm{NO}_{x}$. The mixing occurs after $\mathrm{NO}_{x}$ formation has ceased, but before the combustion chamber bulk temperatures fall below the soot quench temperature $(1400 \mathrm{~K})$. For the Caterpillar 3401 engine considered in the present study, this window of opportunity was between $20 \mathrm{CA}$ ATDC and 60 CA ATDC.

4. High pressure AGI delivery pressure (2000 psi) is required for AGI to occur during the aforementioned window of opportunity. Low delivery pressure postponed AGI until after the combustion chamber bulk temperature had fallen below the soot quench temperature. Thus, neither soot nor $\mathrm{NO}_{x}$ were influenced by low pressure AGI. High pressure AGI at these retarded timings was also ineffective at reducing engineout soot.

5. For the range of oxygen contents considered in this study ( $21 \%$ - $30 \%$ by volume), there was no significant effect from varying the injected gas composition. The range of compositions considered in this study was selected to correspond to the oxygen enrichment levels attainable with present air separation membrane technology.

6. The enhancement of in-cylinder mixing during the later stages of combustion by AGI shortens the duration of the heat release and increases engine power. This increase in power offsets the parasitic power consumption that would be required for a high-pressure air compressor for an AGI combustion system.

\section{Acknowledgment}

This work was supported by the U.S. Department of Energy, Offices of Heavy Vehicle Technologies and Advanced Automotive Technologies under contract W-31-109-Eng38. The authors are grateful to Gurpreet Singh and Ken Howden, Program Managers at DOE for their support of this program.

\section{References}

[1] K. Yamaura, T. Kakegawa, S. Furuhama, T. Suzuki, Y. Kim, and H. Shibuya. A Study for Reduction of Diesel Exhaust Emission by Gas Injection (1st Report: Reduction of Black Smoke by Combustible Gas Injection), volume 123, pages 129-134. Japan, 1990. in Japanese.

[2] R. L. Cole T. J. Marciniak D. E. Longman W. W. Marr, R. R. Sekar, Oxygen-Enriched Diesel Engine Experiments with Low-Grade Fuel. SAE Technical Paper 932805, Society of Automotive Engineers, Warrendale, PA, 1993. 
[3] D. K. Mather, E. M. Kurtz, D. E. Foster, R. B. Poola, D. E. Longman, A. Chanda, and T. J. Vachon. A Parametric Study of the Factors that Influence the Impact of Auxiliary Gas Injection in a DI Diesel Engine . ASME, 2000.

[4] M. A. Patterson, S. C. Kong, G. J. Hampson, and R. D. Reitz, Modeling the Effects of Fuel Injection Characteristics on Diesel Engine Soot and $\mathrm{NO}_{x}$ Emissions. SAE Technical Paper 940523, Society of Automotive Engineers, Warrendale, PA, 1994.

[5] J. Xin, D. Montgomery, and R. D. Reitz. Multidimensional Modeling of Combustion for a Six-Mode Emissions Test Cycle on a DI Diesel Engine. ASME Journal of Engineering for Gas Turbines and Power, 119:683691, 1997.

[6] G. J. Hampson and R. D. Reitz, Two-Color Imaging of In-Cylinder Soot Concentration and Temperature in a Heavy-Duty DI Diesel Engine with Comparison to Multidimensional Modeling for Single and Split Injections. SAE Technical Paper 980524, Society of Automotive Engineers, Warrendale, PA, 1998. 